Check for updates

Cite this: RSC Adv., 2018, 8, 14732

Received 28th February 2018

Accepted 13th April 2018

DOI: 10.1039/c8ra01765d

rsc.li/rsc-advances

\section{A time-of-flight mass spectrometry based strategy to fast screen triterpenoids in Xanthoceras sorbifolia Bunge husks for bioactive substances against Alzheimer's disease $\uparrow$}

\begin{abstract}
Weiwei Rong, Kewen Ding, Sirui Guo, Ziyue Yuan, Qing Li and Kaishun Bi (D) *
Xanthoceras sorbifolia Bunge is a folk medicine in China. Recently, the triterpenoids in its husks have attracted more and more attention for potential prevention against Alzheimer's disease. However, current studies on its bioactive substances were still insufficient. To reveal more bioactive substances, an efficient and practical strategy based on high resolution mass spectra coupled with multiple data mining techniques was developed to characterize the barrigenol type triterpenoids in the husks and dosed rat plasma. A total of 50 barrigenol type triterpenoids were identified in the husks, and 6 of these were detected in the rat plasma, which were regarded as bioactive candidates. To find the real bioactive substances, the neuroprotective effect of the candidates was further tested by calculating the PC12 cell viability against amyloid- $\beta$-induced cytotoxicity. As a result, three out of the six candidates exhibited obvious neuroprotction against amyloid- $\beta$-induced cytotoxicity on PC12 cells, indicating their potential to be bioactive substances against Alzheimer's disease. This study will be a valuable reference of the bioactive substances in Xanthoceras sorbifolia Bunge husks against Alzheimer's disease and the provided strategy can also be applied to the exploration of the effective constituents in other medicines.
\end{abstract}

\section{Introduction}

Xanthoceras sorbifolia Bunge (X. sorbifolia), belonging to Sapindaceae, is a kind of indigenous shrub distributed around the north and northeast of China. ${ }^{1,2}$ Its woods and fruit seeds were used as folk medicines for the treatment of rheumatism and pediatric nocturia. ${ }^{3,4}$ Recent study found that the husks with the advantages of abundant resource and low cost, were a promising medicinal resource. There were various chemical constituents in the husks, like triterpenoid saponins, coumarins, flavonoids and sterols etc. ${ }^{5-8}$ Among them, barrigenol type triterpenoid saponins, rich in the husks, were its characteristic constituents and responsible for its multiple bioactivities, such as antitumor activity, anti-inflammatory activity, and especially the potentiality against Alzheimer's disease (AD). ${ }^{8-10}$ However, current studies on its bioactive substances against $\mathrm{AD}$ were insufficient. Most of them mainly focused on a monomer named xanthoceraside because it was rich in the husks and proved to exhibit excellent protection against amyloid- $\beta$ (A $\beta$ )induced cognitive disorder in rats. ${ }^{11-18}$ The neuroprotection of

National and Local Joint Engineering Laboratory for Key Technology of Chinese Material Medica Quality Control, School of Pharmacy, Shenyang Pharmaceutical University, 103 Wenhua Road, Shenyang 110016, China.E-mail: kaishunbi.syphu@ gmail.com

$\dagger$ Electronic supplementary information (ESI) available. See DOI: 10.1039/c8ra01765d other saponins was rarely reported. For reasonable development and utilization of the husks, sufficient study on its bioactive substances against $\mathrm{AD}$ was very necessary. Nevertheless, intensive research on the neuroprotection of every saponin was time-consuming, labor-intensive and high-cost. According to Serum Pharmacochemistry of Traditional Chinese Medicines (SPT) theory, most bioactive constituents were first absorbed into blood after oral administration, and then exerted therapeutic effect after metabolism and distribution. ${ }^{19}$ Hence, components detected in the dosed plasma were more possible to exert efficacy in practice. Based on this principle, we tried to find an efficient strategy to reveal the bioactive substances.

Thus, firstly, chemical profiling of barrigenol type triterpenoids in the husks was carried out. However, as was widely believed, chemical profiling of traditional chinese medicines (TCMs) was very time-consuming for its various components, complex matrices and unavailable analytical standards. Hence, an efficient and reliable analytical method seemed very important. Conventional techniques such as liquid chromatography and capillary electrophoresis in most cases could not satisfy the analysis of TCMs. In recent decades, high resolution mass spectrometry had gained popularity due to its accurate mass measurement, which simplified the process of identification and the analysis time was thus shortened. ${ }^{\mathbf{2 0}, 21}$ Therefore, in this study, an efficient and reliable ultra-high-performance liquid chromatography combined with electrospray ionization 
quadrupole time-of-flight tandem mass spectrometry (UHPLC/ ESI-Q-TOF-MS/MS) method was established to screen and identify the effective components in $X$. sorbifolia husks. Thousands of high resolution MS and MS/MS data was obtained during chemical profiling. To fast identify target ions from complex interference ions, a powerful data processing tool, PeakView 2.2 software (Sciex, US), was applied to processing the original data automatically based on retention time, accurate mass molecular ion, isotopic pattern, and MS/MS library searching. In general, compounds in the same family were able to yield similar fragment ions or neutral loss molecules after collision induced dissociation (CID). Thus, the modules of the product ion filter (PIF) and neutral loss filter (NLF) within the software were applied to fast screen different kinds of barrigenol type triterpenoids by specifying the values of corresponding fragment ions or neutral loss molecules..$^{22}$ In this way, a large number of barrigenol type triterpenoid saponins in the husks were identified and a database with their detailed information was created. Then, the dosed rat plasma samples were detected using the same method, and barrigenol type triterpenoids absorbed into the blood were fast identified based on the database in vitro, which could be considered as the bioactive candidates. ${ }^{19}$ Finally, the neuroprotective effect of the candidates was further tested by $\mathrm{A} \beta_{25-35}$ induced cytotoxicity on PC12 cells to find the real bioactive substances with the potentiality against $\mathrm{AD} .^{14,23-25}$

Up to now, there were few comprehensive studies on chemical profiling of barrigenol type triterpenoids in $X$. sorbifolia husks. This work not only provided characteristic fragment pathways to fast screen different kinds of barrigenol type triterpenoids in the husks for the first time, but also enriched its bioactive substances studies against $\mathrm{AD}$. In addition, the provided strategy will be very useful for the exploration of effective substances in other medicines.

\section{Experimental}

\subsection{Chemicals and materials}

Chromatographic-grade methanol, acetonitrile and formic acid were supplied from Fisher Scientific (Fair Lawn, NJ, USA) and distilled water was purchased from Wahaha Co. Ltd (Hangzhou, China). Other analytical-grade reagents and solvents were provided by Shandong Yuwang Industrial Co. Ltd. (Yucheng, China).

$X$. sorbifolia husks were obtained from Chifeng city, Inner Mongolia, China, which was identified by Professor Ying Jia (Department of Traditional Chinese Materia Medica, Shenyang Pharmaceutical University, Shenyang, China). A total of 15 reference standards were used for the identification, 9 (compounds 8, 10, 12-14, 16, 17, 33 and 34) of which were isolated by our library and their chemical structures were unambiguously identified by comparing the experimental NMR and HR-MS data with the previous reports. Other 6 reference standards (compounds 18, 22, 26, 36, 39 and 45) were gifts from Professor Dali Meng and Huiyuan Gao (Department of Traditional Chinese Materia Medica, Shenyang Pharmaceutical University, Shenyang, China). The purity of all the reference standards were over $90 \%$ and their structures were listed on Fig. 1.

The PC12 cells were got from BOSTER Biological Technology (Wuhan, China), high glucose-Dulbecco's modified Eagle medium (H-DMEM) was supplied from HYclone (SH30022.01, Lot. B10201637), heat-inactivated fetal bovine serum (FBS) was purchased from Gibco (10099-141 Lot. 1715752) and $A \beta_{25-35}$ was obtained from Sigma Aldrich (St Louis, MO, USA).

\subsection{Preparation of $X$.sorbifolia husks extract}

Dried powdered $X$. sorbifolia husks $(\sim 100 \mathrm{~g})$ were extracted three times with $1000 \mathrm{ml}$ of $70 \%$ ethanol under reflux for $2 \mathrm{~h}$. After filtering, the extraction was combined and concentrated under reduced pressure. The concentrate was redissolved with a concentration of $1 \mathrm{~g}$ crude drug per milliliter in water to obtain the solution and stored it at $4{ }^{\circ} \mathrm{C}$ for animal oral administration.

One milliliter of intragastric administration $\left(1 \mathrm{~g} \mathrm{ml}^{-1}\right)$ was diluted with $10 \mathrm{ml}$ of water and passed through a $0.22 \mu \mathrm{m}$ filter before UHPLC-MS analysis.

\subsection{Animals experiment}

Six healthy male Sprague-Dawley rats $(220 \pm 20 \mathrm{~g})$ were provided by the Experimental Animal Center of Shenyang Pharmaceutical University and bred with free access to food and water in a stable-condition $\left(22 \pm 2{ }^{\circ} \mathrm{C}\right.$ temperature, $40-60 \%$ relative humidity) with a natural light-dark cycle for a week before the experiment to adapt the rats to the environment. Animal study was carried out following the Guideline of Animal Experimentation of Shenyang Pharmaceutical University, and the protocol was approved by the Animal Ethics Committee of the institution.

The rats were fasted $12 \mathrm{~h}$ with free access to water before oral administration of the husks extract at a dose of $10 \mathrm{~g} \mathrm{~kg}^{-1} .1 .0 \mathrm{ml}$ of blood samples were collected from suborbital vein into heparinized tubes before and $2 \mathrm{~h}$ after administration and immediately centrifuged at $1000 \times g$ for $10 \mathrm{~min}$. The plasma samples were combined to make plasma pools, and then stored at $-80{ }^{\circ} \mathrm{C}$ until analysis.

\subsection{Pre-processing of plasma samples}

The frozen plasma samples were first thawed to room temperature. An aliquot of $1 \mathrm{ml}$ of pooling plasma samples was extracted with $3 \mathrm{ml}$ of ethyl acetate and isopropanol $(1: 1, \mathrm{v} / \mathrm{v})$. Then the mixture was vortex-mixed for $3 \mathrm{~min}$ and centrifuged at $10000 \times g$ for $10 \mathrm{~min}$. The supernatant was evaporated to dryness at $30{ }^{\circ} \mathrm{C}$ under a stream of nitrogen, and then redissolved in $100 \mu \mathrm{l}$ of methanol with vortex-mixing for $3 \mathrm{~min}$. The supernatant was acquired after centrifugation at $10000 \times g$ for $5 \mathrm{~min}$ and $5 \mu \mathrm{l}$ was injected into the UHPLC/ESI-Q-TOF-MS/MS system for further analysis.

\section{$2.5 \quad A \beta_{25-35}$ preparation and cell culture}

The core toxic peptide fragment derived from amyloid precursor protein, $\mathrm{A} \beta_{25-35},{ }^{19}$ was dissolved in distilled water to obtain $1 \mathrm{mg}$ 


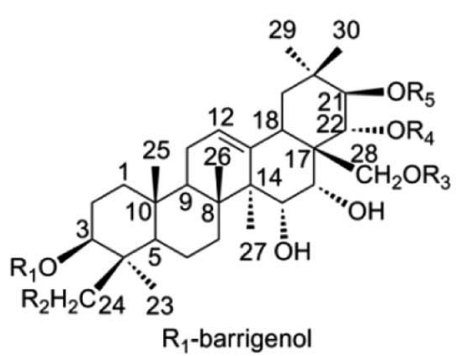

11: $R_{1}=[G \mid c A(2,1)-G a l](3,1)-A r a, R_{2}=H, R_{3}=H, R_{4}=A n g, R_{5}=H$

$21: R_{1}=H, R_{2}=H, R_{3}=$ Glc, $R_{4}=H, R_{5}=$ Ang

$22^{*}: R_{1}=H, R_{2}=H, R_{3}=H, R_{4}=H, R_{5}=H$

23: $1=[\mathrm{GlcA}(2,1)-\mathrm{Gal}](3,1)-A r a, R_{2}=\mathrm{H}, \mathrm{R}_{3}=\mathrm{H}, \mathbf{R}_{4}=\mathrm{H}, \mathbf{R}_{5}=\mathrm{Ang}$

24/27: $R_{1}=[G \mid c A(2,1)-G a l](3,1)-A r a, R_{2}=H, R_{3}=H, R_{4}=A n g, R_{5}=$ OAng

24/27: $R_{1}=[G \mid c A(2,1)-G a l](3,1)-A r a, R_{2}=H, R_{3}=H, R_{4}=O A n g, R_{5}=A n g$

29: $R_{1}=[G|c A(2,1)-G a|](3,1)-A r a, R_{2}=H, R_{3}=H, R_{4}=A n g, R_{5}=$ OAng

30: $R_{1}=[\mathrm{GlcA}(2,1)-\mathrm{Gal}](3,1)-A r a, R_{2}=\mathrm{H}, \mathbf{R}_{3}=\mathrm{H}, \mathbf{R}_{4}=\mathrm{i}-\mathrm{Bu}, \mathbf{R}_{5}=\mathrm{Ang}$

31: $\mathbf{R}_{\mathbf{1}}=[\mathrm{GlcA}(2,1)-\mathrm{Gal}](3,1)$-Ara, $\mathbf{R}_{\mathbf{2}}=\mathrm{OH}, \mathbf{R}_{3}=\mathrm{H}, \mathbf{R}_{\mathbf{4}}=\mathrm{Ang}, \mathbf{R}_{\mathbf{5}}=\mathrm{Ang}$

32: $\mathbf{R}_{1}=\mathrm{H}, \mathbf{R}_{\mathbf{2}}=\mathrm{H}, \mathbf{R}_{3}=\mathrm{H}, \mathbf{R}_{\mathbf{4}}=\mathrm{OAng}, \mathbf{R}_{5}=\mathrm{H}$

$33^{*}: R_{1}=[\mathrm{GlcA}(2,1)-\mathrm{Gal}](3,1)-A r a, \mathbf{R}_{2}=\mathrm{H}, \mathbf{R}_{3}=\mathrm{H}, \mathbf{R}_{4}=$ Ang, $\mathbf{R}_{5}=$ Ang

$34^{*}: R_{1}=\left[\operatorname{GlcA}(2,1)-G\right.$ al] $(3,1)-A r a, R_{2}=H, R_{3}=2$-methylbutanoyl, $R_{4}=H, R_{5}=A n g$

35: $R_{1}=\operatorname{GlcA}(2,1)-G$ al] $(3,1), R_{2}=H, R_{3}=H, R_{4}=A n g, R_{5}=A n g$

$37: R_{1}=H, R_{2}=H, R_{3}=H, R_{4}=H, R_{5}=$ OAng

$39^{*}: \mathbf{R}_{1}=\mathrm{H}, \mathbf{R}_{2}=\mathrm{H}, \mathbf{R}_{\mathbf{3}}=\mathrm{H}, \mathbf{R}_{4}=\mathrm{Ang}, \mathbf{R}_{\mathbf{5}}=\mathrm{H}$

$41: R_{1}=H, R_{2}=\mathrm{OH}, \mathbf{R}_{3}=\mathrm{H}, \mathbf{R}_{\mathbf{4}}=\mathrm{H}, \mathbf{R}_{\mathbf{5}}=\mathrm{Ang}$

43/46: $\mathrm{R}_{1}=\mathrm{H}, \mathrm{R}_{2}=\mathrm{H}, \mathrm{R}_{3}=\mathrm{H}, \mathrm{R}_{\mathbf{4}}=$ Ang, $\mathrm{R}_{5}=$ OAng

43/46: $R_{1}=H, R_{2}=H, R_{3}=H, R_{4}=$ OAng, $R_{5}=A n g$

44: $R_{1}=H, R_{2}=H, R_{3}=H, R_{4}=H, R_{5}=A n g$

48: $\mathbf{R}_{\mathbf{1}}=\mathrm{H}, \mathbf{R}_{\mathbf{2}}=\mathrm{OH}, \mathbf{R}_{\mathbf{3}}=\mathrm{H}, \mathbf{R}_{\mathbf{4}}=\mathrm{Ang}, \mathbf{R}_{\mathbf{5}}=$ Ang

50: $R_{1}=H, R_{2}=H, R_{3}=H, R_{4}=A n g, R_{5}=$ Ang

25/28: $R_{1}=H, R_{2}=H, R_{3}=H, R_{4}=H, R_{5}=H, R_{6}=R h a(4,1)-A c$

25/28: $R_{1}=H, R_{2}=H, R_{3}=A c, R_{4}=H, R_{5}=H, R_{6}=R h a$

$26^{*}: R_{1}=H, R_{2}=H, R_{3}=H, R_{4}=H, R_{5}=H, R_{6}=H$

38: $R_{1}=[\mathrm{GIcA}(2,1)-\mathrm{Gal}](3,1)-\mathrm{Ara}, \mathbf{R}_{2}=\mathrm{OH}, \mathbf{R}_{3}=\mathrm{H}, \mathbf{R}_{4}=\mathrm{H}, \mathbf{R}_{5}=\mathrm{Ang}, \mathbf{R}_{6}=\mathrm{OAng}$

40: $\mathbf{R}_{\mathbf{1}}=\mathrm{H}, \mathbf{R}_{\mathbf{2}}=\mathrm{H}, \mathbf{R}_{\mathbf{3}}=\mathrm{H}, \mathbf{R}_{\mathbf{4}}=\mathrm{H}, \mathbf{R}_{5}=\mathrm{H}, \mathbf{R}_{\mathbf{6}}=[\mathrm{Rha}(3,1)-\mathrm{Ang}](4,1)-\mathrm{Ac}$

42: $R_{1}=H, R_{2}=\mathrm{OH}, R_{3}=H, R_{4}=H, R_{5}=A c, R_{6}=[R h a(3,1)-A n g](4,1)-A c$

45*: $\mathbf{R}_{\mathbf{1}}=\mathrm{H}, \mathbf{R}_{\mathbf{2}}=\mathrm{H}, \mathbf{R}_{\mathbf{3}}=\mathrm{Ac}, \mathbf{R}_{\mathbf{4}}=\mathrm{H}, \mathbf{R}_{\mathbf{5}}=\mathrm{H}, \mathbf{R}_{\mathbf{6}}=\mathbf{R h a}(\mathbf{4}, 1)$-Ang

47: $R_{1}=H, R_{2}=O H, R_{3}=A c, R_{4}=H, R_{5}=H, R_{6}=[R h a(3,1)$-Ang] (4,1)-Ang

49: $R_{1}=H, R_{2}=H, R_{3}=A c, R_{4}=H, R_{5}=H, R_{6}=[R h a(3,1)-A n g](4,1)-A n g$

barringtogenolC

1: $R_{1}=G \mid c(6,1)-G l c, R_{2}=[G \mid c(2,1)-G I c](6,1)-G l c, R_{3}=H$

2: $R_{1}=G I c(6,1)-G l c, R_{2}=[G I c(2,1)-R h a](6,1)-G I c, R_{3}=H$

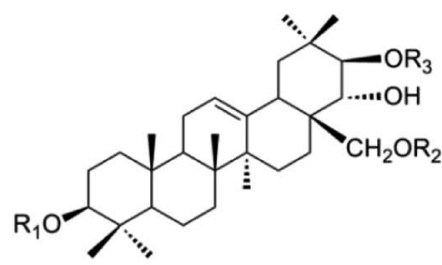

3: $R_{1}=G l c(6,1)-G l c, R_{2}=G l c(2,1)-R_{h a}, R_{3}=H$

4: $R_{1}=G I c, R_{2}=G I c(6,1)-G I c, R_{3}=H$

5: $R_{1}=G l c, R_{2}=G I c(2,1)-R h a, R_{3}=H$

6/7: $R_{1}=G I c, R_{2}=G I c(2,1)-R h a, R_{3}=A c$

$6 / 7: R_{1}=H, R_{2}=[G I c(2,1)-R h a](6,1)-G l c, R_{3}=A c$

$8^{*}: R_{1}=[G \mid c(4,1)-A n g](6,1)-G I c, R_{2}=[G I c(2,1)-R h a](6,1)-G l c, R_{3}=H$

9: $R_{1}=[G \mid c(3,1)-A n g](6,1)-G I c, R_{2}=G I c(6,1)-G I c, R_{3}=H$

10*: $R_{1}=[G \mid c(3,1)-A n g](6,1)-G l c, R_{2}=[G \mid c(2,1)-R h a](6,1)-G l c, R_{3}=H$

12*: $R_{1}=[G I c(4,1)-A n g](6,1)-G I c, R_{2}=G I c(2,1)-R h a, R_{3}=H$

16-deoxybarringtogenol C

13*: $R_{1}=[G I c(2,1)-A n g](6,1)-G l c, R_{2}=[G l c(2,1)-R h a](6,1)-G l c, R_{3}=H$

$14^{*}: R_{1}=[G I c(3,1)-A n g](6,1)-G I c, R_{2}=G I c(2,1)-R h a, R_{3}=H$

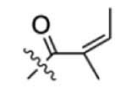

Ang:Angeloyl

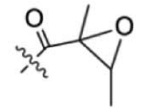

$16^{*}: R_{1}=[G I c(2,1)-A n g](6,1)-G I c, R_{2}=G I c(2,1)-R h a, R_{3}=H$

$17^{*}: R_{1}=[$ [Glc(3,1)-Ang] $(4,1)-A c](6,1)-G l c, R_{2}=[G \mid c(2,1)-R h a](6,1)-G l c, R_{3}=H$

18*: $R_{1}=[G I c(3,1)-A n g](6,1)-G I c, R_{2}=[G I c(2,1)-R h a](6,1)-G I c, R_{3}=A c$

19: $R_{1}=G$ Ic $(3,1)$-Ang, $R_{2}=G$ Ic $(2,1)-R$ ha, $R_{3}=H$

20: $\mathbf{R}_{\mathbf{1}}=\mathrm{H}, \mathbf{R}_{\mathbf{2}}=\mathbf{G l c}, \mathbf{R}_{\mathbf{3}}=\mathrm{H}$

OAng:2,3-dimethyloxiran-2-yl) ethanone $36^{\star}: \mathbf{R}_{1}=\mathbf{H}, \mathbf{R}_{2}=\mathbf{H}, \mathbf{R}_{3}=\mathbf{H}$

Fig. 1 Structures of barrigenol triterpenoids in X. sorbifolia.*: reference standards of barrigenol type triterpenoids.

$\mathrm{ml}^{-1}$ solution. Then the solution was incubated at $37^{\circ} \mathrm{C}$ for 7 days to induce the aggregation of $A \beta_{25-35}$, which exhibited strong neurotoxicity. ${ }^{12}$

The PC12 cells were routinely maintained in H-DMEM supplemented with $10 \%(\mathrm{v} / \mathrm{v})$ heat-inactivated FBS, $100 \mathrm{IU} \mathrm{ml}^{-1}$ penicillin as well as $100 \mathrm{~g} \mathrm{ml}^{-1}$ streptomycin at $37^{\circ} \mathrm{C}$ with $5 \%$ $\mathrm{CO}_{2}$. Culture medium was changed every other day. First, PC12 cells were seeded into 96-well multiplates $\left(1 \times 10^{5}\right.$ cells per ml). $24 \mathrm{~h}$ later, cells were pretreated with $0.005 \mathrm{mg} \mathrm{ml}^{-1}, 0.01 \mathrm{mg}$ $\mathrm{ml}^{-1}, 0.05 \mathrm{mg} \mathrm{ml}^{-1}, 0.1 \mathrm{mg} \mathrm{ml}{ }^{-1}$ test samples and $0.242 \times$ $10^{-3} \mathrm{mg} \mathrm{ml}^{-1}$ huperzine-A, respectively. After $24 \mathrm{~h}, \mathrm{~A} \beta_{25-35}(20$ $\mu \mathrm{M})$ was added and incubated for an extra $24 \mathrm{~h}$.

\subsection{Measurement by MTT}

MTT ( $5 \mathrm{mg} \mathrm{ml}^{-1}$ ) was added into the $\mathrm{A}_{25-35}$ induced PC12 cells and incubated per well for $4 \mathrm{~h}$. MTT reduction assay was used to reveal the effects of the barrigenol type triterpenoid saponins. The MTT formazan crystals were solubilized by DMSO and spectrophotometrically measured at $490 \mathrm{~nm}$. The percentage of cell viability was calculated as follows,

Cell viability $(\%)=$ OD test/OD control $\times 100 \%$.

The results were expressed as mean \pm standard deviation. The data was analysed with one-way analysis of variance in SPSS 19.0 software. 


\subsection{Instrumentation and analytical conditions}

UHPLC/ESI-Q-TOF-MS/MS analytical procedure was performed on an AB SCIEX TripleTOF ${ }^{\mathrm{TM}} 5600$ quadrupole-time-of-flight hybrid mass spectrometer (Sciex, Redwood City, CA, USA) coupled with an Agilent 1260 HPLC (Billerica, USA). The chromatographic separation was achieved on a high pressure column prefilter $(2.1 \times 5 \mathrm{~mm}, 2.7 \mu \mathrm{m}$, USA, Agilent $)$ protected Poroshell 120 SB-C18 $(2.1 \times 100 \mathrm{~mm}, 2.7 \mu \mathrm{m}$, USA, Agilent $)$ column at $25{ }^{\circ} \mathrm{C}$. The mobile phase system consisted of $0.1 \%$ formic acid (A) and $0.1 \%$ formic acid in acetonitrile (B). The 50.0 min gradient program was as follows, $10 \% \mathrm{~B} \rightarrow 45 \% \mathrm{~B}$ at $0.01-20.00 \mathrm{~min} ; 45 \% \mathrm{~B} \rightarrow 90 \% \mathrm{~B}$ at $20.01-40.00 \mathrm{~min} ; 90 \% \mathrm{~B}$ at 40.01-43.00 $\mathrm{min}$; $10 \% \mathrm{~B}$ remained for the final $7 \mathrm{~min}$. Efficient and symmetrical peaks were achieved at a flow rate of 0.3 $\mathrm{ml} \min ^{-1}$ with a sample injection volume of $5 \mu \mathrm{l}$.

The TOF MS and CID MS/MS data was collected in both positive and negative electrospray ionization mode (ESI+/-) with dynamic background subtraction. The optimized operating parameters were listed as follows, source temperature, $550{ }^{\circ} \mathrm{C}$; ion spray voltage, $5500 \mathrm{~V}(\mathrm{ESI}+) /-4500 \mathrm{~V}(\mathrm{ESI}-)$; nebulizer gas, 50 psi; heater gas, 50 psi; curtain gas, 30 psi; declustering potential, $80 \mathrm{~V}(\mathrm{ESI}+) /-80 \mathrm{~V}(\mathrm{ESI}-)$; collision energy, $10 \mathrm{~V}$ $(\mathrm{ESI}+) /-10 \mathrm{~V}(\mathrm{ESI}-)$. Information dependent acquisition were operated by a TOF-MS survey scan 100-1500 Da (100 ms) and up to 8 dependent TOF-MS/MS scans 50-1500 Da (100 ms) using collision energy of $60 \mathrm{~V}(\mathrm{ESI}+) /-60 \mathrm{~V}$ (ESI-) with collision energy spread of $\pm 15 \mathrm{~V}$. Mass tolerance was set as $50 \mathrm{mDa}$ and continuous recalibration was executed every fifth injection using the calibrant delivery system. Operations and acquisition were all edited in the Analyst TF 1.6 software panel (Sciex, USA).

\section{Results and discussion}

\subsection{Chemical profiling by UHPLC/ESI-Q-TOF-MS/MS}

Barrigenol type triterpenoid saponins in X. sorbifolia husks were reported to exhibit multiple bioactivities, including alleviating cognitive deficits, antitumor activities and anti-inflammatory etc. ${ }^{4,10-17}$ According to the presence of hydroxy at C-15 and/or C-16 and/or C-21 and/or C-22, they can be divided into three groups, known as barringtogenol C, R1-barrigenol and 16deoxybarringtogenol C. ${ }^{8}$ PIF and NLF in PeakView ${ }^{\circledR} 2.2$ software was chosen to fast screen compounds in different types by specifying the values of the corresponding fragment ions or neutral loss molecules. ${ }^{26}$ The maximum tolerance of mass error was set as 5 ppm. Fragment ions in positive mode were selected to demonstrate the fragment pattern since higher sensitivity and more fragment ions were obtained. A total of 50 triterpenoid saponins were identified preliminarily and their structures were shown in Fig. 1. Among them, 15 triterpenoids were unambiguously identified by comparing with the standards, other 25 triterpenoids were tentatively identified based on the reported information, and the rest 10 were first identified in this study. Information of all the compounds was listed in Table S1 $\uparrow$ and their XIC spectra were shown in Fig. S1(A and B). $\dagger$

A total of twenty-one R1-barrigenol type triterpenoids were detected in husks extract with the same aglycone structure as shown in Fig. 1. Sugar groups at C-3 as well as angeloyl groups at C-21 and/or C-22 were eliminated easily from the aglycone by CID. As a result, sugar moiety ions such as $493.11(-\mathrm{GlcA}+\mathrm{Gal}+$ Ara) and 343.06 (-GlcA + Gal) were generated in the MS/MS spectra. To illustrate the possible fragmentation pathway in detail, one of the most abundant and widely reported saponins, xanthoceracide (compound 33), was selected as an instance. As shown in Fig. 2(A), the precursor ion $[\mathrm{M}+\mathrm{Na}]^{+}$at $m / z 1163.5598$ was yielded, indicating a molecular formula of $\mathrm{C}_{57} \mathrm{H}_{88} \mathrm{O}_{23}$ in ESI $(+)$ mode. Fragment ions at $m / z 693.4310$ was generated by the loss of the sugar group (-Ara-Gal-GluA) and $m / z 593.3803$ was further produced by the loss of an angeloyloxy group. In addition, product ions at $m / z$ 493.1149 $[\mathrm{Ara}+\mathrm{Gal}+\mathrm{GluA}+\mathrm{Na}]^{+}$ and $m / z 343.0636$ [GlcA + Gal- $\left.\mathrm{H}_{2} \mathrm{O}+\mathrm{Na}\right]^{+}$were also observed, indicating the composition of the sugar group at C-3. In the same way, other 14 R1-barrigenol type triterpenoids were identified preliminary, ${ }^{26-30}$ among which, compounds 22, 34 and 39 were undoubted identified by comparing with the authentic standards. Then PIF and NLF modules were applied to explore unreported compounds. The product ion at $\mathrm{m} / \mathrm{z}$ 493.11 was taken as an example to illustrate the detailed process. As Fig. S2(A and B) $\dagger$ showed, after filtering process, interference peaks disappeared obviously and target peaks highlighted. After careful analysis, compounds $\mathbf{2 4}$ and 27 were picked out particularly since they were not searched in Chemspider online library or previous references. Their MS information indicated that they shared the same molecular formula with compound 31, whereas, their fragment pathways were different (Fig. S2(C and D)). $\dagger$ In the MS/MS spectra of compounds 24 and 27, fragment ion at $\mathrm{m} / \mathrm{z} 709.43$ was observed, 116 Da more than $\mathrm{m} / \mathrm{z} 593.38$, suggesting the oxidation of one of the angeloyloxy groups. However, the accurate oxidized site was difficult to be confirmed only by the limited mass spectra information. The same strategy offered another four new ones (compounds 32, 37, 43 and 46) and their possible identities were listed in Table $\mathrm{S} 1 . \dagger$

For barringtogenol $\mathrm{C}$ type triterpenoids, functional groups were always substituted at C-21 (-Rha-Ang/-Rha-Ac) and/or C$16 / 22 / 28$ (-Ac) of the aglycone, where the linkages could be broken easily by CID. Product ions of the aglycone like $\mathrm{m} / \mathrm{z}$ 477.33 and $\mathrm{m} / \mathrm{z} 495.34$ were thus obtained. According to different substituent groups, different fragment ions such as $m / z 229.06$ refers to $[\mathrm{Rha}+\mathrm{Ac}+\mathrm{Na}]^{+}, m / z 269.09$ refers to $[\mathrm{Rha}+$ $\mathrm{Ang}+\mathrm{Na}]^{+}, m / z 311.10$ refers to $[\mathrm{Rha}+\mathrm{Ang}+\mathrm{Ac}+\mathrm{Na}]^{+}$and $m / z$ 351.14 refers to $[\mathrm{Rha}+2 \mathrm{Ang}+\mathrm{Na}]^{+}$were generated. For instance, compound $\mathbf{4 0}$ produced the precursor ion at $\mathrm{m} / \mathrm{z}$ $783.4643\left(\mathrm{C}_{43} \mathrm{H}_{68} \mathrm{O}_{11}\right)$ as well as a group of characteristic fragment ions at $m / z 723.4404,495.3408$ and 477.4332, corresponding to the loss of $60 \mathrm{Da}$ (OAc), $288 \mathrm{Da}$ (Ac + Ang + Rha$\left.\mathrm{H}_{2} \mathrm{O}\right)$ and $306 \mathrm{Da}(\mathrm{Ac}+\mathrm{Ang}+\mathrm{Rha})$, respectively. Furthermore, product ion at $\mathrm{m} / \mathrm{z} 269.0990$ was also generated; suggesting one angeloyl group was substituted on the rhamnose. Based on the above information and previous reports, compound $\mathbf{4 0}$ was tentatively identified as $21-O$-(4- $O$-acetyl-3- $O$-angeloyl)- $\beta$-Dfucopyranosyl theasapogenol. ${ }^{27}$ Its detailed fragment pathway was illustrated in Fig. 2(B). Likewise, compounds 42, 45, 47 and 49 were also tentatively identified. ${ }^{29,30}$ Particularly, 

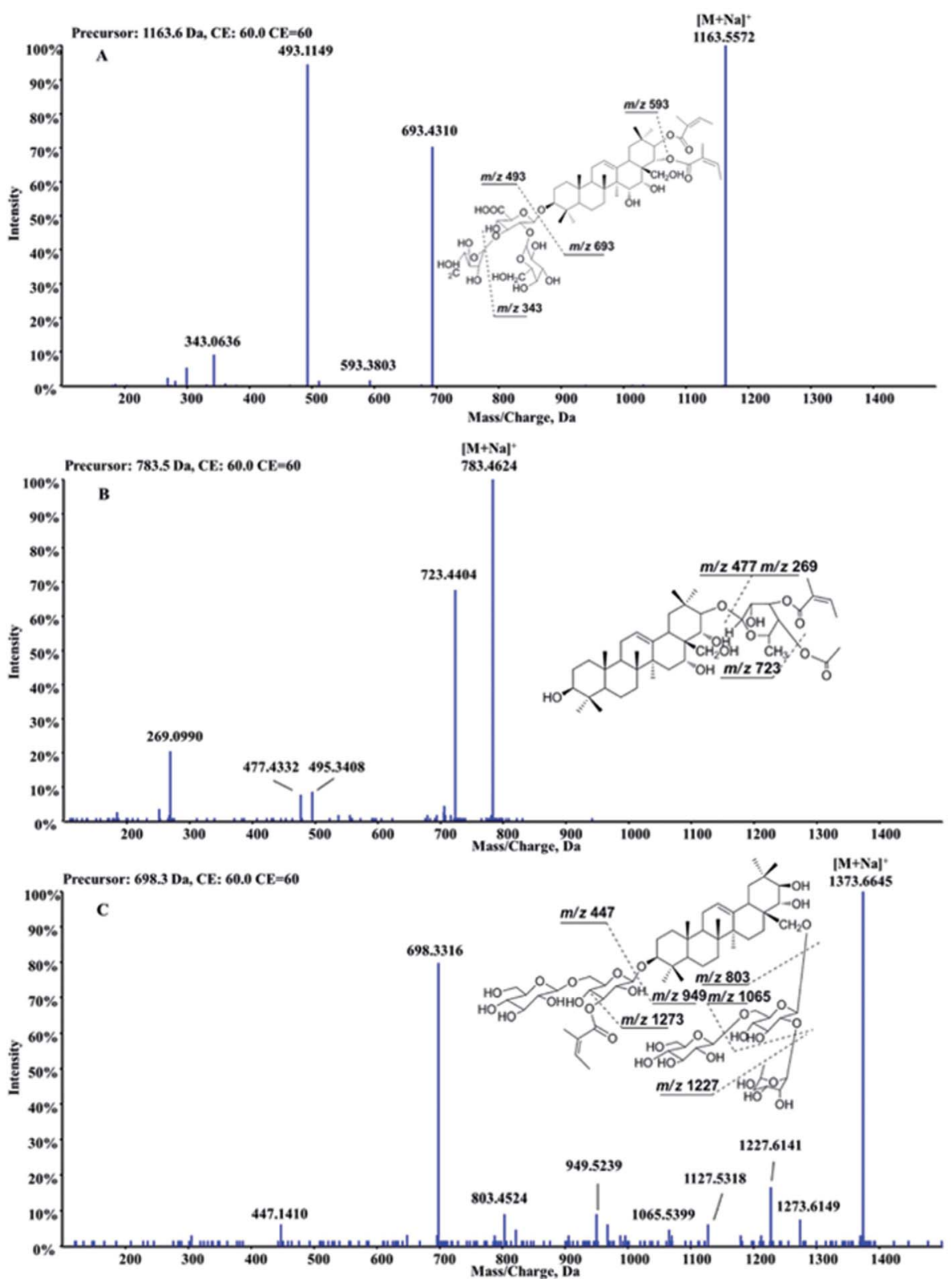

Fig. 2 The characteristic fragment pathways of barrigenol triterpenoids in X. sorbifolia husks. (A): R1-Barrigenol triterpenoid saponin (compound 33); (B): barringtogenol $C$ triterpenoid saponin (compound 40); (C): 16-dexoybarringtogenol $C$ triterpenoid saponin (compound 10).

compounds 25 and 28 were highlighted after PIF and NLF since they were not detected in Chemspider online library.

A total of twenty 16-deoxybarringtogenol C type triterpenoids were identified in this study, which shared the same aglycone structure named 16-deoxybarringtogenol C (compound 36). Glycosyl groups consisted of glucose, rhamnose and/or angeloyl group were always substituted at C-3 and/or C-28. Thus, successive or simultaneous losses of sugar groups were observed in their MS/MS spectra. Take compound $\mathbf{1 0}$ as an instance (Fig. 2(C)) to explain the fragment pattern. A significant precursor ion $[\mathrm{M}+2 \mathrm{Na}]^{2+}(m / z$ 698.3306) in (+) ESI-MS was yielded, suggesting a molecular formula of $\mathrm{C}_{65} \mathrm{H}_{106} \mathrm{O}_{29}$. Then fragment ions such as $\mathrm{m} / \mathrm{z}$ 1273.6149, $\mathrm{m} / \mathrm{z} 1227.6141, \mathrm{~m} / \mathrm{z}$
1127.5318, $\mathrm{m} / \mathrm{z} 1065.5399, \mathrm{~m} / \mathrm{z} 949.5239$ and $\mathrm{m} / \mathrm{z} 821.4626$ were produced by the loss of 100 Da (-Ang), 146 Da (-Rha), 246 Da (-Rha-Ang), $308 \mathrm{Da}$ (-Glc-Rha), $424 \mathrm{Da}$ (-2Glc-Ang) and $552 \mathrm{Da}$ $\left(-2 \mathrm{Glc}-\mathrm{Rha}-\mathrm{Ang}+\mathrm{H}_{2} \mathrm{O}\right)$, respectively. In addition, fragment ion $[2 \mathrm{Glc}+\mathrm{Ang}+\mathrm{Na}]^{+}$at $\mathrm{m} / \mathrm{z} 447.1410$ was also observed in its MS/ MS spectrum, indicating the composition of sugar groups at C3. Likewise, other nineteen 16-dexoybarringtogenol $\mathrm{C}$ type triterpenoids were tentatively identified, among which, compounds 6 and 7 were new.

In conclusion, a practical and reliable UHPLC-ESI-MS/MS method was first established for chemical profiling of barrigenol type triterpenoid saponins in $X$. sorbifolia husks extract, and a database with detailed information was shown in Table $\mathrm{S} 1, \dagger$ 
which was very helpful for further exploration of bioactive substances.

\subsection{Detection of barrigenol type triterpenoid saponins in rat plasma after oral administration of $X$. sorbifolia husks}

TCMs usually exhibit advantages on the treatment of chronic and complicated disease for its characteristic of multicomponents, -targets and -pathways. However, it is too difficult to illustrate the molecular mechanism and effective substances thoroughly due to the diversity of its components. Intensive study on the efficacy of every chemical component was time-consuming and unreasonable since TCMs exert therapeutic effects depended on the contribution of multiple constituents rather than individual ones. To solve the problem, SPT theory was proposed in early $1990 \mathrm{~s},{ }^{31}$ providing an efficient approach to discovery bioactive constituents which really worked in practice. It stated that most bioactive constituents in TCMs were firstly absorbed into blood after oral administration, and then exerted therapeutic effects after a series of complicated distribution and metabolism. Therefore, constituents in the dosed plasma are more possible to work in practice.

Current study on the bioactive substances of the husks against $\mathrm{AD}$ was insufficient. To discover the bioactive substances more efficiently, our attention was mainly focused on the constituents absorbed into blood. Their spectral information was collected by UHPLC/ESI-Q-TOF-MS/MS and analysed with PeakView ${ }^{\circledR} 2.2$ software at the same condition with Section 3.1. The compounds present in the dosed plasma and absent in the blank samples were selected. The prototype compounds could be fast identified by comparison with the information of database established in vitro. Eventually, only 6 prototype compounds, including four 16-deoxybarringtogenol C type triterpenoids, one barringtogenol $\mathrm{C}$ type triterpenoid and one R1-barrigenol type triterpenoid were identified in dosed plasma. XIC spectra of all the 6 compounds were shown in Fig. S1(C-F). $\dagger$ Neither phase I nor phase II saponins metabolites were detected in the plasma samples after oral administration of the husks, although a lot of attempts were tried in the preexperiments, including different pre-treatment methods (precipitation protein by methanol or acetonitrile, liquid-liquid extraction by ethyl acetate and isopropanol $(1: 1, \mathrm{v} / \mathrm{v})$, and solid phase extraction by Waters Oasis) and detection of plasma samples at different time points $(0.5 \mathrm{~h}, 1 \mathrm{~h}, 2 \mathrm{~h}, 4 \mathrm{~h}, 6 \mathrm{~h}, 8 \mathrm{~h}$ and $12 \mathrm{~h}$ ). The results indicated that some of the barrigenol type triterpenoid saponins probably exerted efficacy as prototype components through absorbing into blood, while, others were probably to work in other ways, which needed further study. The speculation was consistent with the characteristics of TCMs, known as multi-components, targets and pathways.

\subsection{Effect on A $\beta$-induced PC12 cells damage}

In the work, up to 50 barrigenol type triterpenoid saponins were tentatively identified, which could be divided into three types, known as R1-barrigenol type triterpenoid saponin, 16-deoxybarringtogenol $\mathrm{C}$ type triterpenoid saponin and barringtogenol C saponin. ${ }^{8,32}$ Among them, only one R1-barrigenol type triterpenoid saponin (compound 33), rich in the husks, had been reported as the effective substance against AD. ${ }^{14-18}$ There are few reports on other saponins for the difficulty of their effective separation and complete identification. As shown in Fig. 1, the structures of saponins in the same type were very similar, and their sugar chains usually contain 3 to 5 sugar residues, suggesting their high structural complexity, which resulted in the difficulty to obtain their standards. Fortunately, more than compound 33, some 16-deoxybarringtogenol C type triterpenoid saponins were also isolated and identified successfully in our previous study, ${ }^{9}$ two of which (compound 10 and 17) were detected in the dosed rat plasma, implying their potentiality to work in practice according to SPT theory. Since little information was available on their neuroprotection, their neuroprotective effect was further tested by $A \beta_{25-35}$ induced cytotoxicity on PC12 cells. It was worth mentioning that compared to compound 33 , the number and site of sugar groups and angeloyl groups on compound 10 and 17 were different. Therefore, we speculated the neuroprotection of compound $\mathbf{1 0}$ and $\mathbf{1 7}$ were probably different with the reported compound 33. To verify our speculation, the neuroprotective effect of compound $\mathbf{3 3}$ was also tested to compare to compound 10 and 17.

The test of $A \beta_{25-35}$ induced PC12 cells was widely applied to fast screen the compounds with potential neuroprotective effect. ${ }^{14,23-25}$ After $24 \mathrm{~h}$ incubating with the 3 saponins (compounds 10,17 and 33), the viability of PC12 cells was tested by MTT analysis. Fig. 3 demonstrated that the viability of the model groups, exposure to $20 \mu \mathrm{M} \mathrm{A} \beta_{25-35}$ for $24 \mathrm{~h}$, significantly degenerated compared with the control groups $(p<0.05)$, confirming the successful establishment of the model.

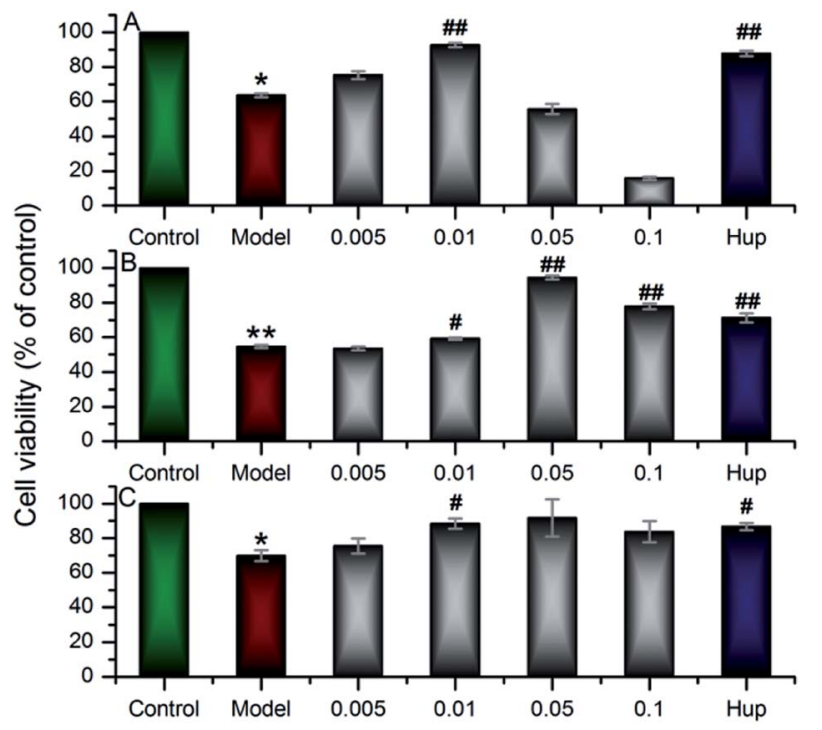

Fig. 3 MTT result in PC12 validation test. $Y$-axis, cell viability (\%); $X$ axis, the order from left to right: control $(100 \%)$, model $\left(A \beta_{25-35}, 20\right.$ $\mu \mathrm{M})$, the concentration gradient of the test samples $\left(0.005 \mathrm{mg} \mathrm{ml}^{-1}\right.$, $0.01 \mathrm{mg} \mathrm{ml}^{-1} ; 0.05 \mathrm{mg} \mathrm{ml}^{-1}$ and $\left.0.1 \mathrm{mg} \mathrm{ml}^{-1}\right)$, the concentration of huperzine-A $\left(0.242 \times 10^{-3} \mathrm{mg} \mathrm{ml}^{-1}\right)$. (A): Compound 33; (B): compound 10; (C): compound 17. ${ }^{*} p<0.05$ and $* * p<0.01$ vs. control; $\# p<0.05$ and $\# \# p<0.01$ vs. model. 
As shown in Fig. 3, compound 33 (xanthoceracide) exhibited a significant decrement on $\mathrm{A} \beta_{25-35}$ induced PC12 cell death at a concentration of $0.01 \mathrm{mg} \mathrm{ml}^{-1}$, whereas, it exhibited a strong cytotoxicity at a concentration of $0.1 \mathrm{mg} \mathrm{m}{ }^{-1}$, which was consistent with previous research. ${ }^{4,14}$ As a kind of 16-deoxybarringtogenol $\mathrm{C}$ type triterpenoid saponin, compound $\mathbf{1 0}$ exhibited significant neuroprotective effect at the concentration between $0.01 \mathrm{mg} \mathrm{ml}^{-1}$ and $0.1 \mathrm{mg} \mathrm{ml}^{-1}$, and the best neuroprotective effect was shown at the concentration of $0.05 \mathrm{mg}$ $\mathrm{ml}^{-1}$. Similarly, the other 16-deoxybarringtogenol C type triterpenoid saponin, compound $\mathbf{1 7}$, also exhibited significantly neuroprotection at the concentration of $0.01 \mathrm{mg} \mathrm{ml}^{-1}$. At the higher concentration ( $\left.0.1 \mathrm{mg} \mathrm{ml}^{-1}\right)$, compounds 10 and 17 both exhibited much weaker cytotoxicity than compound 33. This phenomena could be explained by the presence of sugar groups at C-28 as well as the absence of angeloyl groups at C-21 and/or $\mathrm{C}-22 .^{4,8,32}$ The result suggested that the three compounds were all the bioactive substances of the husks against $\mathrm{AD}$, but compound 10 and 17 belonging to 16-deoxybarringtogenol C type triterpenoid saponins showed weaker cytotoxicity than compound $\mathbf{3 3}$ at higher concentration. The neuroprotection of compound 10 and 17 was reported for the first time, which will be an important reference for the further development of the husks.

\section{Conclusions}

In this study, a practical and efficient strategy was developed to reveal the bioactive substances of $X$. sorbifolia husks, systemically. A total of 50 barrigenol type triterpenoids were found in husks extract by an UHPLC-ESI-MS/MS method, 6 of which were detected in the dosed plasma as bioactive candidates based on the SPT theory. The neuroprotection of the candidates was further tested by $A \beta_{25-35}$ induced cytotoxicity on PC12 cells. As a result, three candidates, known as compounds 10, 17 and 33, exhibited significant neuroprotection against $A \beta_{25-35}$ induced cytotoxicity on PC12 cells, indicating their potentiality against AD. The neuroprotection of compounds $\mathbf{1 0}$ and $\mathbf{1 7}$ was reported for the first time. This work provided a significant reference for the study of effective constituents in medicines.

\section{Conflicts of interest}

The authors declare that they have no conflict of interest.

\section{Acknowledgements}

This work was supported by the Key Technologies of Common Quality Evaluation of New Drugs (Grant No. 2015010201) and National Natural Science Foundation of China (Grant No. U1508220).

\section{References}

1 S. Zhang, Y. G. Zu, Y. J. Fu, M. Luo, W. Liu, J. Li and T. Efferth, Bioresour. Technol., 2010, 101, 2537-2544.
2 Z. Y. Yao, J. H. Qi and L. M. Yin, Renewable Sustainable Energy Rev., 2013, 24, 57-65.

3 J. Li, Y. G. Zu, Y. J. Fu, Y. C. Yang, S. M. Li, Z. N. Li and M. Wink, Innovative Food Sci. Emerging Technol., 2010, 11, 637-643.

4 W. Xiao, Y. Wang, P. Zhang, N. Li, S. Jiang, J. H. Wang, J. Huang and X. Li, Eur. J. Med. Chem., 2013, 60, 263-270.

5 N. Li, Y. Wang, X. Z. Li, H. Zhang, D. Zhou, W. L. Wang, W. Li, X. R. Zhang, X. Y. Li, Y. Hou and D. L. Meng, Bioorg. Med. Chem. Lett., 2016, 26, 5018-5023.

6 Y. Zhang, J. N. Ma, C. L. Ma, Z. Qi and C. M. Ma, Chin. J. Nat. Med., 2015, 13, 873-880.

7 G. S. Wan, X. B. Wang, L. J. Wu and H. Y. Gao, Chin. Tradit. Herb. Drugs, 2013, 13, 1842-1851.

8 D. Wang, D. Su, X. Z. Li, D. Liu, R. G. Xi, H. Y. Gao and X. B. Wang, RSC Adv., 2016, 6, 27434-27446.

9 J. H. Ling, L. L. Liu, X. Y. Wang, Z. Y. Li, R. Liu, Q. Li, Y. Wang, B. Z. Yang, X. H. Chen and K. S. Bi, J. Pharm. Biomed. Anal., 2011, 55, 259-264.

10 Y. J. Li, J. K. Xu, P. Xu, S. J. Song, P. Liu, T. Y. Chi, X. F. Ji, G. Jin, S. M. Qiu, Y. P. Hou, C. Zheng, L. L. Wang, D. L. Meng and L. B. Zou, Neurosci. Lett., 2016, 629, 208-214.

11 Y. Qi, L. B. Zou, L. H. Wang, G. Jin, J. J. Pan, T. Y. Chi and X. F. Ji, J. Pharmacol. Sci., 2013, 122, 305-317.

12 X. F. Ji, T. Y. Chi, Q. Xu, X. L. He, X. Y. Zhou, R. Zhang and L. B. Zou, J. Evidence-Based Complementary Altern. Med., 2014, 2014, 969342.

13 P. Lu, T. Mamiya, L. L. Lu, A. Mouri, T. Ikejima, H. C. Kim, L. B. Zou and T. Nabeshima, Psychopharmacology, 2012, 219, 181-190.

14 P. Liu, L. B. Zou, Q. Jiao, T. Y. Chi, X. F. Ji, Y. Qi, Q. Xu and L. H. Wang, Neurosci. Lett., 2013, 543, 115-120.

15 T. Y. Chi, L. H. Wang, X. F. Ji, L. Shen and L. B. Zou, J. Asian Nat. Prod. Res., 2013, 15, 1013-1022.

16 T. Y. Chi, L. H. Wang, C. Qu, B. Z. Yang, X. F. Ji, Y. Wang, T. Okuyama, O. Shihito and B. Zou, J. Asian Nat. Prod. Res., 2009, 11, 1019-1027.

17 G. Jin, L. H. Wang, X. F. Ji, T. Y Chi, Y. Qi, Q. Jiao, Q. Xu, X. Y. Zhou, R. Zhang and L. B. Zou, Neurosci. Lett., 2014, 573, 58-63.

18 D. L. Meng, L. Shang, X. H. Feng, X. F. Huang and X. Che, Int. J. Pharm., 2016, 506, 184-190.

19 X. J. Wang, A. H. Zhang, H. Sun, Y. Han and G. L. Yan, TrAC, Trends Anal. Chem., 2016, 76, 86-94.

20 Q. Liang, H. Liu, H. T. Xing, Y. Jiang, T. Y. Zhang and A. H. Zhang, RSC Adv., 2016, 6, 29863-29868.

21 L. F. Lin, H. M. Lin, M. Zhang, X. X. Dong, X. B. Yin, C. H. Qu and J. Ni, RSC Adv., 2015, 5, 107623-107636.

22 X. Zhang, C. J. Liang, J. T. Yin, Y. P. Sun and L. T. Zhang, RSC $A d v .$, 2018, 8, 11813-11827.

23 J. Nie, Y. Tian, Y. Zhang, Y. L. Lu, L. S. Li and J. S. Shi, PeerJ, 2016, 4, e2739.

24 H. X. Zhang, Y. Z. Cao, L. X. Chen, J. J. Wang, Q. H. Tian, N. Wang, Z. J. Liu, J. Li, N. Wang, X. K. Wang, P. Y. Sun and L. H. Wang, Carbohyd. Polym., 2015, 117, 879-886.

25 C. M. Wang, M. Y. Liu, F. Wang, M. J. Wei, S. Wang, C. F. Wu and J. Y. Yang, Pharmacol., Biochem. Behav., 2013, 106, 57-67. 
26 Z. L. Li, X. Li, L. H. Li, N. Li, M. Yu and D. L. Meng, Planta Med. Lett., 2005, 71, 1068-1070.

27 G. S. Wan, X. B. Wang, L. J. Wu and H. Y. Gao, Chin. Herb. Med., 2013, 44, 1842-1851.

28 W. Li, X. Li, D. L. Meng, P. Zhang and Z. L. Li, J. Asian Nat. Prod. Res., 2007, 9, 7-11.
29 Y. J. Chen, T. Takeda and Y. Ogihara, Chem. Pharm. Bull., 1985, 33, 127-134.

30 Y. J. Chen, T. Takeda and Y. Ogihara, Chem. Pharm. Bull., 1985, 33, 1387-1394.

31 X. J. Wang, China J. Chin. Mater. Med., 2006, 31, 789-792.

32 D. Wang, D. Su, B. Yu, C. M. Chen, L. Cheng, X. Z. Li, R. G. Xi, H. Y. Gao and X. B. Wang, Fitoterapia, 2017, 116, 51-60. 